\title{
ANALISIS MANAJEMEN STRATEGI DALAM MENINGKATKAN DAYA SAING SEKOLAH DASAR NURTURE SPRING JAKARTA
}

\author{
Cindy \\ Program Studi Magister Manajemen Universitas Tarumanagara \\ cindysamue12610@gmail.com \\ Eko Harry Susanto \\ Program Studi Magister Manajemen Universitas Tarumanagara \\ Masuk : 26-05-2020, revisi : 24-06-2020 diterima untuk diterbitkan : 24-06-2020
}

\begin{abstract}
This study aims to analyze the management strategies that Nurture Spring Primary School can implement in improving its competitiveness. This study applies qualitative methods through conducting interviews and observations by directly reviewing the research object. The analysis method consists of the input stage, matching stage, and decision stage. At the input stage an analysis is carried out with Internal Factor Evaluation, External Factor Evaluation, and CPM Matrix. The matching stage is carried out using the SWOT matrix, Internal - External matrix, and the SPACE matrix. The decision stage is analyzed by using QSPM matrix. From the results of the study, it was found that the strategy obtained from the QSPM matrix is a market penetration strategy with a TAS value of 7.005. This strategy is the most appropriate strategy that can applied for Nurture Spring Primary School. The school must use its internal strength in maintaining existing market shares.
\end{abstract}

Abstrak : Penelitian ini bertujuan untuk menganalisis manajemen strategi yang dapat diterapkan SD Nurture Spring dalam meningkatkan daya saingnya. Penelitian ini menerapkan metode kualitatif, dengan melakukan wawancara serta observasi dengan meninjau langsung objek penelitian. Metode Analisis yang dilakukan terdiri tahap input, tahap pencocokan, dan tahap keputusan. Pada tahap input dilakukan analisis dengan Internal Factor Evaluation, External Factor Evaluation, dan Matriks CPM. Tahap pencocokan dilakukan dengan matriks SWOT, matriks Internal - External, dan matriks SPACE. Pada tahap keputusan dilakukan analisis dengan matriks QSPM. Dari hasil penelitian, diperoleh bahwa strategi yang diperoleh dari matriks QSPM adalah strategi penetrasi pasar dengan nilai TAS sebesar 7,005. Strategi ini merupakan strategi yang paling tepat untuk diterapkan untuk SD Nurture Spring. Sekolah harus menggunakan kekuatan internal dalam mempertahankan pangsa pasar yang sudah ada.

Kata Kunci : Perencanaan Strategis, Sekolah Dasar, Matriks IFE, EFE, SPACE, SWOT, QSPM, Peningkatan Daya Saing Sekolah

\section{PENDAHULUAN}

Sekolah Nurture Spring memberikan pendidikan holistik, di mana siswa tidak hanya unggul secara akademis tetapi juga unggul dalam semua aspek lainnya yaitu pembangunan fisik dan pembangunan sosial. Perkembangan Sekolah Nurture Spring sudah semakin meningkat. Banyak aspek yang saling mempengaruhi agar sekolah ini tetap eksis dalam jangka waktu yang panjang. Hal-hal tersebut mencakup hal-hal eksternal dan internal. Penelitian yang dilakukan diharapkan dapat menjadi bahan evaluasi dan perencanaan strategi Sekolah Nurture Spring melalui manajemen strategi untuk peningkatan kualitas dan juga sebagai penyedia jasa agar sekolah ini dapat terus berkembang ke arah yang lebih baik ke depannya. Tujuan Penulisan ini adalah untuk mengetahui penilaian yang dilakukan Sekolah Nurture Spring terhadap lingkungan persaingannya, untuk mengetahui faktor-faktor yang mempengaruhi strategi 
Sekolah Nurture Spring, untuk mengetahui strategi Sekolah Nurture Spring sebagai lembaga pendidikan untuk Sekolah Dasar dalam bersaing.

\section{TINJAUAN PUSTAKA}

Manajemen strategi bisa didefinisikan sebagai suatu rangkaian keputusan dan tindakan yang menghasilkan formulasi, mengimplementasikannya, dan mengevaluasi lintas fungsional keputusan yang memungkinkan untuk mencapai tujuannya. Pada tahap formulasi strategi dibagi menjadi 3 tahap, yaitu: input stage, matching stage, dan decision stage.

Input stage terdiri dari:

1. Matriks IFE : analisis yang berguna dalam mengidentifikasi kekuatan dan kelemahan suatu perusahaan atas dasar sumber daya dan kapabilitas yang dimilikinya

2. Matriks EFE: analisis yang berguna dalam mengidentifikasi peluang dan ancaman suatu perusahaan yang berasal dari luar lingkungan perusahaan

3. Matriks CPM: mengidentifikasi perusahaan dengan kompetitor dalam bidang usaha yang sama dilihat dari beberapa aspek seperti strength, weakness, opportunity, dan threat (SWOT).

Matching stage terdiri dari:

1. Matriks IE: menganalisis kondisi kerja dan posisi strategis bisnis

2. Analisis SWOT: suatu kerangka logis yang ditujukan membantu para manajer guna mempertimbangkan secara hati-hati kapabilitas internal perusahaan dan menggunakan hasilnya untuk membentuk pilihan strategis

3. Matriks SPACE: merupakan alat analisis lainnya pada tahap 2 untuk menunjukkan apakah strategi agresif, konservatif, defensif, atau kompetitif adalah strategi yang paling tepat untuk dilakukan pada suatu organisasi.

Decision stage terdiri dari:

1. Matriks QSPM: analisis yang memungkinkan ahli strategi untuk mengevaluasi strategi alternatif secara objektif, berdasarkan pada faktor keberhasilan kritis eksternal dan internal yang sebelumnya diidentifikasi

\section{METODE PENELITIAN}

Metode penelitian yang dilakukan dalam penelitian ini adalah metode kualitatif, yaitu penelitian yang bertujuan untuk menggambarkan situasi dan karakteristik sebenarnya menyangkut objek penelitian. Metode deskriptif digunakan untuk menguraikan tentang sifatsifat atau karakteristik suatu keadaan. Pengumpulan data: (1) Data primer adalah teknik pengumpulan data yang diperoleh secara langsung pada objek penelitian ini. Data primer yang dikumpulkan dan diperlukan dalam penelitian ini adalah observasi dan wawancara. (2) Data Sekunder adalah data yang diperoleh dari sumber lain, seperti melalui studi literatur mengenai strategi dan pemasaran, serta mencari data-data tambahan melalui sumber-sumber terpercaya.

\section{HASIL DAN PEMBAHASAN TAHAP INPUT}

\section{Tabel 1}

Matriks IFE SD Nurture Spring

\begin{tabular}{|c|c|c|c|}
\hline Faktor-faktor Strategi Internal & Weight & Rating & Weighted Score \\
\hline $\begin{array}{l}\text { Kekuatan: } \\
\text { 1. } \text { Kurikulum pelajaran yang bagus dan mengombinasikan } \\
\text { antara pelajaran dan praktik } \\
\text { 2. Kualitas pengajar } \\
\text { 3. Kemampuan manajemen internal yang baik } \\
\text { 4. Hubungan antar karyawan yang terjalin dengan baik } \\
\text { 5. Budaya organisasi di tempat kerja yang baik } \\
\text { 6. Penggunaan bahasainggris sebagai bahasa pengantar utama } \\
\text { 7. } \\
\text { Keikutsertaan pendidik dalam kegiatan pengembangan } \\
\text { profesi }\end{array}$ & $\begin{array}{l}0,112 \\
0,098 \\
0,075 \\
0,033 \\
0,063 \\
0,047 \\
0,025 \\
0,035\end{array}$ & $\begin{array}{l}4 \\
3 \\
3 \\
4 \\
3 \\
3 \\
3\end{array}$ & $\begin{array}{l}0,448 \\
0,392 \\
0,225 \\
0,099 \\
0,252 \\
0,141 \\
0,075 \\
0,105\end{array}$ \\
\hline
\end{tabular}




\begin{tabular}{|c|c|c|c|}
\hline $\begin{array}{ll}\text { 8. } & \text { Memiliki nilai akreditasi A } \\
\text { 9. } & \text { Memiliki prestasi akademik yang baik } \\
\text { 10. } & \text { Kegiatan sekolah yang mendukung karakter anak }\end{array}$ & $\begin{array}{l}0,053 \\
0,045\end{array}$ & $\begin{array}{l}4 \\
3\end{array}$ & $\begin{array}{l}0,212 \\
0,135\end{array}$ \\
\hline $\begin{array}{l}\text { Kelemahan: } \\
\text { 1. Kurangnya sarana dan prasarana (lapangan olahraga, } \\
\text { kantin) } \\
\text { 2. Ruang kelas yang kecil dan agak sempit } \\
\text { 3. Biaya sekolah dengan fasilitas penunjang kegiatan belajar } \\
\text { masih kurang seimbang } \\
\text { 4. Baru meluluskan dua angkatan } \\
\text { 5. Sekolah Nurture Spring belum terlalu dikenal oleh } \\
\text { masyarakat luas } \\
\text { 6. Ketidaksesuaian kualifikasi bidang ilmu dengan mata } \\
\text { pelajaran yang diajarkan } \\
\text { 7. Pemasaran terbatas untuk internal } \\
\text { 8. Lokasi yang berada di dalam kompleks }\end{array}$ & $\begin{array}{l}0,105 \\
0,083 \\
0,054 \\
0,047 \\
0,036 \\
0,031 \\
0,035 \\
0,023\end{array}$ & $\begin{array}{l}2 \\
2 \\
2\end{array}$ & $\begin{array}{c}0,21 \\
0,166 \\
0,108 \\
0,047 \\
0,072 \\
0,031 \\
0,035 \\
0,046\end{array}$ \\
\hline
\end{tabular}
kuat.

Weighted score melebihi skor rata-rata 2,5 yang mengindikasikan posisi internal yang

\section{Tabel 2}

Matriks EFE SD Nurture Spring

\begin{tabular}{|c|c|c|c|}
\hline Faktor-faktor Strategi Eksternal & Weight & Rating & Weighted Score \\
\hline Peluang: & & & \\
\hline 1. Semakin banyaknya kegiatan pengembangan profesi guru & 0,071 & 2 & 0,142 \\
\hline 2. Kesadaran orang tua terhadap pentingnya kualitas & 0,085 & 3 & 0,255 \\
\hline pendidikan & 0,112 & 4 & 0,448 \\
\hline 3. Banyaknya media pembelajaran & 0,103 & 4 & 0,412 \\
\hline 4. Kemajuan teknologi yang mendukung dalam pembelajaran & 0,062 & 2 & 0,124 \\
\hline 5. Dukungan pemerintah akan pendidikan & 0,083 & 2 & 0,166 \\
\hline 6. Orang tua secara turun temurun menyekolahkan anaknya & 0.097 & 3 & 201 \\
\hline 7. Motivasi dan kemauan yang tinggi dari SDM & 0,096 & $\begin{array}{l}3 \\
4\end{array}$ & $\begin{array}{l}0,291 \\
0,384\end{array}$ \\
\hline $\begin{array}{l}\text { 8. Tren menyekolahkan anak di sekolah yang menggunakan } \\
\text { bahasa Inggris sebagai bahasa pengantar }\end{array}$ & & & \\
\hline Ancaman: & & & \\
\hline 1. Kompetisi mutu dengan sekolah lainnya yang sejenis & 0,117 & 4 & 0,468 \\
\hline $\begin{array}{l}\text { 2. Biaya yang ditawarkan sekolah lain ada yang berada di } \\
\text { bawah biaya Nurture Spring }\end{array}$ & 0,096 & 3 & 0,288 \\
\hline 3. Peranan orang tua yang dominan terhadap sekolah & 0,078 & 2 & 0,156 \\
\hline Total & 1,00 & & 3,134 \\
\hline
\end{tabular}

Sekolah Nurture Spring dapat menghadapi ancaman dan memanfaatkan peluang dengan baik karena weighted score dari tabel EFE ini melebihi 2,50.

\section{Tabel 3}

CPM SD Nurture Spring

\begin{tabular}{|c|c|c|c|c|c|c|c|}
\hline \multirow{2}{*}{$\begin{array}{c}\text { Faktor Penentu } \\
\text { Keberhasilan }\end{array}$} & \multirow{2}{*}{ Weight } & \multicolumn{2}{|c|}{ SD Nurture Spring } & \multicolumn{2}{c|}{ SD Kasih Immanuel } & \multicolumn{2}{c|}{ SD Kairos Gracia } \\
\cline { 3 - 8 } & & Rating & Score & Rating & Score & Rating & Score \\
\hline Sistem pembelajaran & 0,20 & 4 & 0,80 & 3 & 0,60 & 4 & 0,80 \\
\hline Fasilitas & 0,15 & 2 & 0,30 & 2 & 0,30 & 4 & 0,60 \\
\hline Biaya & 0,20 & 3 & 0,60 & 3 & 0,60 & 2 & 0,40 \\
\hline Reputasi sekolah & 0,15 & 4 & 0,60 & 4 & 0,60 & 4 & 0,60 \\
\hline Lokasi & 0,15 & 2 & 0,30 & 2 & 0,30 & 2 & 0,30 \\
\hline SDM Pengajar & 0,15 & 3 & 0,30 & 2 & 0,45 & 3 & 0,45 \\
\hline Total & $\mathbf{1 , 0 0}$ & & $\mathbf{2 , 9}$ & & $\mathbf{2 , 8 5}$ & & $\mathbf{3 , 1 5}$ \\
\hline
\end{tabular}

Hasil analisis CPM dapat disimpulkan bahwa sekolah Nurture Spring memiliki beberapa nilai yang cukup tinggi dengan pesaingnya. Namun, Sekolah Nurture Spring cukup tertinggal dalam hal fasilitas sehingga hal ini harus menjadi salah satu strategi Sekolah Nurture Spring guna meningkatkan daya saing. 


\section{TAHAP PENCOCOKAN}

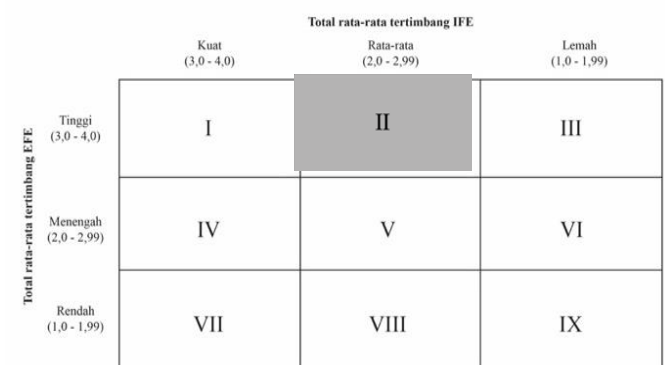

Diagram 1

Matriks IE SD Nurture Spring Jakarta

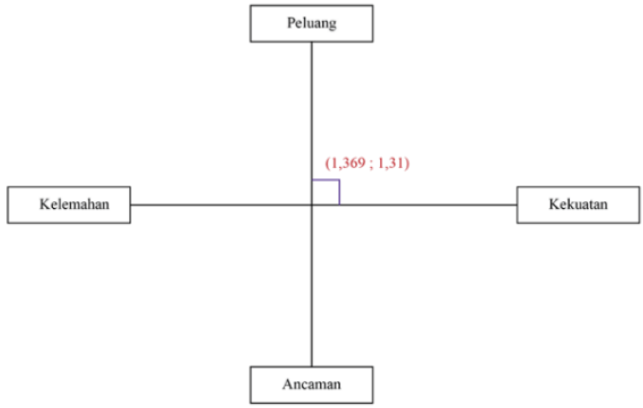

Diagram 2

Matriks SWOT SD Nurture Spring Jakarta

Weighted Score dari matriks IFE adalah 2,799 dan weighted score dari matriks EFE adalah 3,134. Dari hasil penyusunan kedua matriks tersebut, maka posisi strategi bisnis SD Nurture Spring berada pada kuadran II dengan strategi Grow and built strategies.

Total Skor Bobot Kekuatan - Total Skor Bobot Kelemahan =2,084 - 0,715 = 1,369

Total Skor Bobot Peluang - Total Skor Bobot Ancaman = 2,222- 0,912 = 1,31

Berdasarkan gambar diketahui kuadran hasil EFAS dan IFES berada pada kuadran I. Maka strategi yang cocok dengan kondisi internal maupun eksternal adalah menjalankan strategi SO (strategi menggunakan kekuatan untuk mencapai peluang).

Strategi SO :

1. Mengembangkan pembelajaran yang aktif, inovatif, kreatif, efektif, dan menyenangkan sesuai kurikulum

2. Meningkatkan pembelajaran yang meningkatkan pembangunan karakter yang baik bagi anak

3. Meningkatkan sosialisasi kepada orang tua mengenai kualitas sekolah, baik dari pengajar maupun kurikulum

4. Meningkatkan kemampuan bahasa Inggris untuk semua tenaga pendidikan

5. Mengembangkan program character building

Tabel 4

Matriks Space

\begin{tabular}{|c|c|c|c|}
\hline Posisi Strategis Internal & Rating & Posisi Strategis Eksternal & Rating \\
\hline $\begin{array}{l}\text { Finance Strength (FS) } \\
\text { 1. Dukungan pemerintah berupa dana } \\
\text { 2. Keadaan ekonomi orang tua } \\
\text { 3. Unit produksi }\end{array}$ & $\begin{array}{l}5 \\
2 \\
2\end{array}$ & $\begin{array}{l}\text { Enviromental Stability (ES) } \\
\text { 1. Kompetisi mutu dengan sekolah lainnya yang } \\
\text { sejenis } \\
\text { 2. Kemajuan teknologi yang mendukung dalam } \\
\text { pembelajaran } \\
\text { 3. Motivasi belajar siswa }\end{array}$ & $\begin{array}{l}-3 \\
-3 \\
-2\end{array}$ \\
\hline Total FS & 9 & Total ES & -8 \\
\hline Rata-rata FS & 3 & Rata-rata ES & $-2,67$ \\
\hline $\begin{array}{ll} & \text { Competitive Advantage (CA) } \\
\text { 1. } & \text { Kurikulum sekolah } \\
\text { 2. } & \text { Kegiatan sekolah } \\
\text { 3. } & \text { Fasilitas sekolah }\end{array}$ & $\begin{array}{l}-1 \\
-2 \\
-4\end{array}$ & \begin{tabular}{ll} 
& \multicolumn{1}{c}{ Industry Strength (IS) } \\
1. & Sarana dan prasarana \\
2. & Guru dan tenaga pendidik \\
3. & Standar pengelolaan
\end{tabular} & $\begin{array}{l}1 \\
3 \\
2\end{array}$ \\
\hline Total CA & -7 & Total IS & 6 \\
\hline Rata-rata CA & $-2,33$ & Rata-rata IS & 2 \\
\hline
\end{tabular}




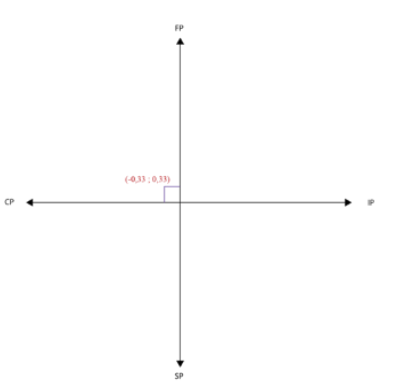

Diagram 3

Analisis Matriks SPACE TAHAP KEPUTUSAN

Dari total nilai rating yang ada, maka dilakukan perhitungan untuk mendapatkan posisi kuadran pada gambar, sehingga diperoleh strategi berdasarkan analisis matriks SPACE.

Garis Vertikal $=\mathrm{FS}+\mathrm{ES}=3+(-2,67)=0,33$

Garis Horizontal $=\mathrm{CA}+\mathrm{IS}=-2,33+2=-0,33$

Berdasarkan gambar dapat disimpulkan bahwa secara kuadran konservatif, maka strategi yang cocok untuk diterapkapkan adalah penetrasi pasar, pengembangan pasar, dan pengembangan produk.

\section{Tabel 5}

Matriks Perencanaan Strategis Kuantitatif (QSPM)

\begin{tabular}{|c|c|c|c|c|c|c|c|}
\hline \multirow{3}{*}{ Faktor-Faktor Utama } & \multirow{3}{*}{ Bobot } & \multicolumn{6}{|c|}{ Alternatif Strategi } \\
\hline & & \multicolumn{2}{|c|}{$\begin{array}{l}\text { Penetrasi } \\
\text { Pasar }\end{array}$} & \multicolumn{2}{|c|}{$\begin{array}{l}\text { Pengembangan } \\
\text { Pasar }\end{array}$} & \multicolumn{2}{|c|}{$\begin{array}{l}\text { Pengembangan } \\
\text { Produk }\end{array}$} \\
\hline & & $\mathbf{A S}$ & TAS & $\mathbf{A S}$ & TAS & $\mathbf{A S}$ & TAS \\
\hline \multicolumn{8}{|l|}{ Kekuatan } \\
\hline Kurikulum pelajaran yang bagus & 0,112 & 4 & 0,448 & 4 & 0,448 & 4 & 0,448 \\
\hline Kualitas pengajar & 0,098 & 4 & 0,392 & 4 & 0,392 & 4 & 0,392 \\
\hline Kemampuan manajemen internal yang baik & 0,075 & 4 & 0,3 & 2 & 0,45 & 4 & 0,3 \\
\hline $\begin{array}{l}\text { Hubungan antar karyawan yang terjalin dengan } \\
\text { baik }\end{array}$ & 0,033 & 4 & 0,132 & 2 & 0,066 & 4 & 0,132 \\
\hline Budaya organisasi di tempat kerja yang baik & 0,063 & 4 & 0,252 & 2 & 0,126 & 3 & 0,189 \\
\hline $\begin{array}{l}\text { Penggunaan bahasa inggris sebagai bahasa } \\
\text { pengantar utama }\end{array}$ & 0,047 & 3 & 0,141 & 3 & 0,141 & 3 & 0,141 \\
\hline $\begin{array}{l}\text { Keikutsertaan pendidik } \\
\text { pengembangan profesi }\end{array}$ & 0,025 & 3 & 0,075 & 2 & 0,05 & 4 & 0,1 \\
\hline Memiliki nilai akreditasi A & 0,035 & 1 & 0,035 & 3 & 0,105 & 1 & 0,035 \\
\hline Memiliki prestasi akademik yang baik & 0,053 & 4 & 0,212 & 3 & 0,159 & 2 & 0,196 \\
\hline Kegiatan sekolah yang mendukung karakter anak & 0,045 & 4 & 0,18 & 3 & 0,135 & 2 & 0,09 \\
\hline \multicolumn{8}{|l|}{ Kelemahan } \\
\hline $\begin{array}{l}\text { Kurangnya sarana dan prasarana (lapangan } \\
\text { olahraga, kantin) }\end{array}$ & 0,105 & 4 & 0,42 & 4 & 0,42 & 4 & 0,42 \\
\hline Ruang kelas yang kecil dan agak sempit & 0,083 & 3 & 0,249 & 4 & 0,332 & 3 & 0,249 \\
\hline $\begin{array}{l}\text { Biaya sekolah dengan fasilitas penunjang kegiatan } \\
\text { belajar masih kurang seimbang }\end{array}$ & 0,054 & 4 & 0,216 & 4 & 0,216 & 2 & 0,108 \\
\hline Baru meluluskan dua angkatan & 0,047 & 2 & 0,094 & 2 & 0,094 & 1 & 0,047 \\
\hline $\begin{array}{l}\text { Sekolah Nurture Spring belum terlalu dikenal oleh } \\
\text { masyarakat luas }\end{array}$ & 0,036 & 2 & 0,072 & 3 & 0,216 & 3 & 0,216 \\
\hline $\begin{array}{l}\text { Ketidaksesuaian kualifikasi bidang ilmu dengan } \\
\text { mata pelajaran yang diajarkan }\end{array}$ & 0,031 & 2 & 0,062 & 1 & 0,031 & 3 & 0,093 \\
\hline Pemasaran terbatas untuk internal & 0,035 & 3 & 0,105 & 3 & 0,105 & 2 & 0,07 \\
\hline Lokasi yang berada di dalam kompleks & 0,023 & 3 & 0,069 & 4 & 0,092 & 1 & 0,023 \\
\hline \multicolumn{8}{|l|}{ Peluang } \\
\hline $\begin{array}{l}\text { Semakin banyaknya kegiatan pengembangan } \\
\text { profesi guru }\end{array}$ & 0,071 & 4 & 0,284 & 1 & 0,071 & 4 & 0,284 \\
\hline $\begin{array}{l}\text { Kesadaran orang tua terhadap pentingnya kualitas } \\
\text { pendidikan }\end{array}$ & 0,085 & 4 & 0,34 & 3 & 0,255 & 3 & 0,255 \\
\hline Banyaknya media pembelajaran & 0,112 & 4 & 0,448 & 2 & 0,224 & 4 & 0,448 \\
\hline $\begin{array}{l}\text { Kemajuan teknologi yang mendukung dalam } \\
\text { pembelajaran }\end{array}$ & 0,103 & 4 & 0,412 & 3 & 0,309 & 4 & 0,412 \\
\hline Dukungan pemerintah akan pendidikan & 0,062 & 3 & 0,186 & 2 & 0,124 & 3 & 0,186 \\
\hline $\begin{array}{l}\text { Orang tua secara turun temurun menyekolahkan } \\
\text { anaknya di sekolah yang sama }\end{array}$ & 0,083 & 4 & 0,332 & 1 & 0,083 & 1 & 0,083 \\
\hline Motivasi dan kemauan yang tinggi dari SDM & 0,097 & 4 & 0,388 & 2 & 0,194 & 4 & 0,388 \\
\hline $\begin{array}{l}\text { Tren menyekolahkan anak di sekolah yang } \\
\text { menggunakan bahasa Inggris sebagai bahasa } \\
\text { pengantar }\end{array}$ & 0,096 & 4 & 0,384 & 3 & 0,288 & 1 & 0,096 \\
\hline \multicolumn{8}{|l|}{ Ancaman } \\
\hline $\begin{array}{l}\text { Kompetisi mutu dengan sekolah lainnya yang } \\
\text { sejenis }\end{array}$ & 0,117 & 3 & 0,351 & 4 & 0,468 & 4 & 0,468 \\
\hline
\end{tabular}




\begin{tabular}{|l|c|c|c|c|c|c|c|}
\hline $\begin{array}{l}\text { Biaya yang ditawarkan sekolah lain ada yang } \\
\text { berada di bawah biaya Nurture Spring }\end{array}$ & 0,096 & 2 & 0,192 & 4 & 0,384 & 4 & 0,384 \\
\hline Peranan orang tua yang dominan terhadap sekolah & 0,078 & 3 & 0,234 & 1 & 0,078 & 3 & 0,234 \\
\hline Total & & & $\mathbf{7 , 0 0 5}$ & & $\mathbf{6 . 0 5 6}$ & & $\mathbf{6 , 4 8}$ \\
\hline
\end{tabular}

Dari hasil analisis matriks QSPM didapatkan strategi penetrasi pasar, yaitu sekolah harus menggunakan kekuatan internal dalam mempertahankan pangsa pasar yang sudah ada, seperti dengan menggiatkan promosi baik untuk internal maupun eskternal, membuat iklan yang menarik mengenai kekuatan internal sekolah dan melakukan pemasaran melalui media elektronik, membuat program menarik untuk uji coba bagi anak-anak TK yang ingin bersekolah di Nurture Spring seperti belajar sambil praktik dan bermain, memberi potongan harga kepada orang tua yang menyekolahkan anaknya lebih dari satu orang dan kepada orang tua yang mempromosikan sekolah kepada kerabatnya, serta mengefektifkan penggunaan media sosial sebagai promosi maupun komunikasi dua arah dengan orang tua murid.

\section{DAFTAR PUSTAKA}

Bunnel, Tristan. (2005). Strategic Marketing Planning in International Schools. International Journal of Educational Management, 19 (1), 59 - 66

David, Fred R. (2011). Strategic Management : Concept and Cases (13 ${ }^{\text {th }}$ ed.). New Jersey : Pearson Education Inc.

Depdiknas. (2007). Manajemen Peningkatan Mutu Berbasis Sekolah, Konsep dan Pelaksanaan. Jakarta : Dirjen Dikdasmen.

Ebrahimi, Ali, \& Hamidreza Banaeifard. (2018). The Influence of Internal and External Factors on The Marketing Strategic Planning in SNOWA Corporation. Journal of Business \& Industrial Marketing, 33. 10.1108/JBIM-02-2018-0083.

Kotler, P., Hermawan Kartajaya, \& Iwan Setiawan. (2019). Marketing 4.0 : Bergerak dari Tradisional ke Digital. Jakarta : PT. Gramedia Pustaka Utama.

Hariastuti, Ni Luh Putu.(2010). Strategic Management Planning Improving The Quality of Education High School.

Kotler, P. \& Keller, K.L. (2009). Marketing Management (13th ed.). New Jersey : Pearson Education Inc.

Li, Chen-Ying, Liwei Hsu \& Yi Hsu .(2011). The Analysis of Factors Affect Stakeholders' Decision for Choosing Schools : A Study in Taiwan. International Journal of Current Research, 3 (9), 138-144.

Malik, Syed Abdul, Salman Bin Abdulaziz, Nasser Saad Al Khatani, Mohammad Naushad. (2013). Integrating Ahp, SWOT and QSPM in Strategic Planning-An Application To College of Business Administration in Saudi Arabia. International Journal of Academic Research, 5, 373-379. 10.7813/2075-4124.2013/5-5/B.58.

Osman, Mariana Mohamed, \& Noor Alyani Yacob. (2014). Factors Influencing Parents' Decision in Choosing Private Schools. Procedia - Social and Behavioral Sciences, 153, $242-253$.

Pearce II, John A., \& Robinson, Richard B. (2011). Strategic Management : Formulation, Implementation and Control (12 ${ }^{\text {th }}$ ed.). New York : Mc Graw Hill.

Schiffman, Leon G., \& Joseph L. Wisenblit. (2015). Consumer Behavior (11 ${ }^{\text {th }}$ ed.). Pearson Education Inc.

Sugiyono. (2004). Metode Penelitian Kuantitatif, Kualitatif, dan R\&D. Bandung : Alfabeta.

Sujoko, Edi. (2017). Strategi Peningkatan Mutu Sekolah Berdasarkan Analisis SWOT di Sekolah Menengah Pertama, 4 (1), 83-96.

Supranto, J. (2012). Metode Rise t: Aplikasinya dalam Pemasaran. Jakarta : PT. Rineka Cipta.

Susanto, Eko Harry. (2018). Komunikasi Manusia : Teori dan Praktek dalam Penyampaian Gagasan. Jakarta : Penerbit Mitra Wacana Media.

Usman, Husaini. (2006). Manajemen Teori, Praktik dan Riset Pendidikan. Jakarta : Bumi Aksara. 